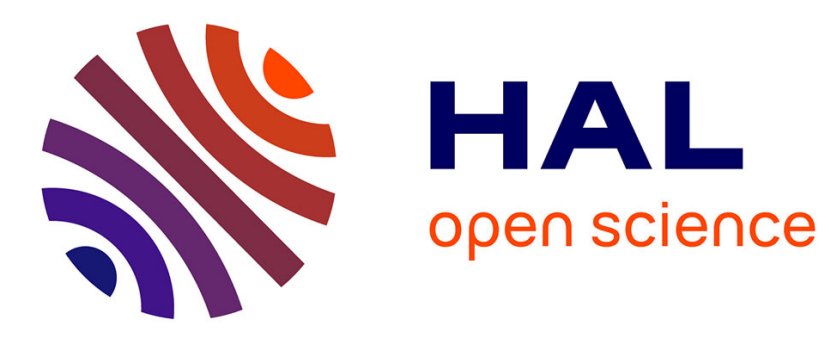

\title{
Lubrication theory of smectic A phases
}

P. Oswald, M. Kléman

\section{- To cite this version:}

P. Oswald, M. Kléman. Lubrication theory of smectic A phases. Journal de Physique Lettres, 1982, 43 (12), pp.411-415. 10.1051/jphyslet:019820043012041100 . jpa-00232069

\section{HAL Id: jpa-00232069 https://hal.science/jpa-00232069}

Submitted on 1 Jan 1982

HAL is a multi-disciplinary open access archive for the deposit and dissemination of scientific research documents, whether they are published or not. The documents may come from teaching and research institutions in France or abroad, or from public or private research centers.
L'archive ouverte pluridisciplinaire HAL, est destinée au dépôt et à la diffusion de documents scientifiques de niveau recherche, publiés ou non, émanant des établissements d'enseignement et de recherche français ou étrangers, des laboratoires publics ou privés. 


\title{
LE JOURNAL DE PHYSIQUE-LETTRES
}

J. Physique - LETTRES 43 (1982) L-411 - L-415

15 JUIN 1982, PAGE L-411

Classification

Physics Abstracts

$61.30 \mathrm{~J}-61.70 \mathrm{G}-47.15$

\section{Lubrication theory of smectic A phases (*)}

\author{
P. Oswald and M. Kléman \\ Laboratoire de Physique des Solides, Bât. 510, Université de Paris-Sud, 91405 Orsay Cedex, France
}

(Reçu le 24 mars 1982, accepté le 26 avril 1982)

\begin{abstract}
Résumé. - Nous adaptons au cas smectique la théorie classique de la lubrification et montrons que la relaxation plastique par montée de dislocations coin régit complètement le phénomène, qui est quantitativement plus important que dans le cas classique. Nous montrons l'existence d'une vitesse critique d'apparition d'une instabilité d'ondulation des couches directement reliée à la mobilité des dislocations. Nous comparons les résultats obtenus avec l'expérience.
\end{abstract}

\begin{abstract}
We adapt to the smectic case the classical lubrication theory; plastic relaxation by edge dislocations climb is the controlling factor of the process, which appears to be more efficient than in the classical case. We show the existence of a critical velocity for the appearance of the undulation instability of the layers, related to the mobility of the dislocations. We compare these results to experiment.
\end{abstract}

1. Introduction. - When a liquid is sheared between two planar surfaces making a small angle $\alpha$, a large pressure is set up, under certain conditions, in the fluid. The lubrication theory is founded on this process [1]. By replacing the liquid by a smectic A one clearly expects similar effects, or even more spectacular, since, apart from the easy flow of the layers past one another, there is a genuine solid-like strength perpendicular to the layers. That is the problem we analyse in the present note.

2. Plastic relaxation under shear. - Figure 1 shows the sample geometry. The upper and lower slides make a small angle $\alpha$. At the point $x$, the thickness reads :

$$
d=d_{1}-\alpha x \text {. }
$$

$\left.{ }^{*}\right)$ Version anglaise d'une Note présentée par M. J. Friedel à l'Académie des Sciences. 


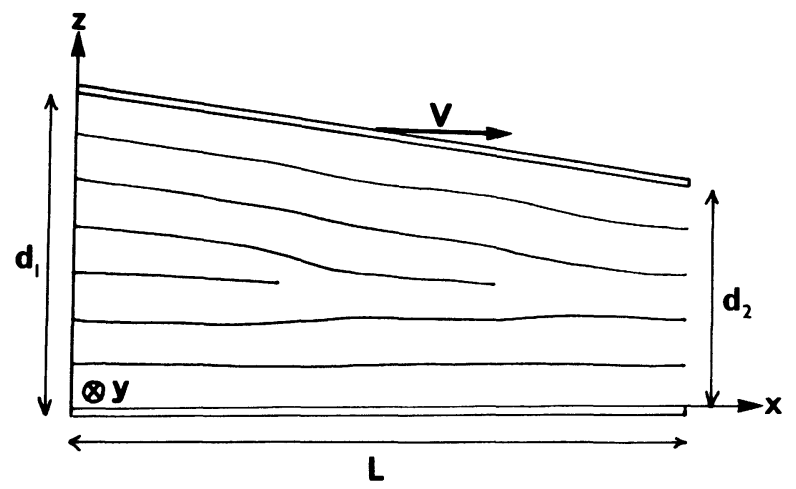

Fig. 1. - Sample geometry.

We impose an orientation parallel to the slides (strong anchoring) upon the smectic layers. The layers being hardly compressible and the slides being at an angle, the spatial variation of the thickness induces within the sample a pattern of edge dislocations parallel to the wedge of the dihedron [2]. Let $b$ be their Burgers vector; the average distance between them is $\Lambda=b / \alpha$.

At time $t=0$, we give to the upper slide a constant and horizontal speed $V$. Because of the easy glide of the layers past one another, the velocity profile is to a good approximation (cf. $\S 4)$ :

$$
V_{x}=V \frac{z}{d}
$$

At time $t$ the thickness of the sample has varied, perpendicularly to a fixed station by an amount :

$$
d=V t \alpha \text {. }
$$

Let us assume that the edge dislocations are motionless : then the smectic is compressed (or dilated according to the sign of $V$ ) by this same amount. In fact this stress acts on the dislocations and makes them climb together in a direction which favours the relaxation of the imposed compression (resp. dilation). Let $v(t)$ be their velocity at time $t$. The relaxed thickness variation reads :

$$
\frac{b}{\Lambda} \int_{0}^{t} v(t) \mathrm{d} t=\alpha \int_{0}^{t} v(t) \mathrm{d} t .
$$

Finally the smectic undergoes an effective thickness variation :

$$
\alpha\left(V t-\int_{0}^{t} v(t) \mathrm{d} t\right)
$$

associated with a uniaxial stress normal to the layers :

$$
\sigma_{z z}=B \frac{\alpha}{d}\left(V t-\int_{0}^{t} v(t) \mathrm{d} t\right)
$$

where $B$ is the bulk modulus. We are now in a position to write the equation of the motion of the dislocations. The stress $\sigma_{z z}$ exerts a Peach and Koehler's force horizontally and equal to $\alpha_{z z} b$ which opposes a friction force $\mu \kappa b V_{\mathrm{r}}[3]$ where $V_{\mathrm{r}}$ is the relative velocity of the dislocation in the 
flow, $\kappa^{-1}=\left(\mu \lambda_{\mathrm{p}}\right)^{1 / 2}$ a permeation distance and $\mu$ the viscosity. In the middle of the sample the speed of the flow is approximately $V / 2(2)$; hence

$$
V_{\mathrm{r}}=v(t)-\frac{V}{2} \text {. }
$$

Equating these two forces, we obtain the following and fundamental equation :

$$
B \frac{\alpha}{d}\left(V t-\int_{0}^{t} v(t) \mathrm{d} t\right)=\mu \kappa\left[v(t)-\frac{V}{2}\right]
$$

which integrates immediately to :

$$
v(t)=V\left[1-\frac{1}{2} \exp \left(-\frac{t}{\tau_{1}}\right)\right]
$$

where $\tau_{1}$ is a characteristic time to move the edge dislocations :

$$
\tau_{1}=\frac{\mu \kappa d}{B \alpha} .
$$

At $t=0$, the dislocations have the same velocity $V / 2$ as the flow which drives them. Then they are accelerated by the external stress $\sigma_{z z}$ and reach a limiting speed $V$ equal to that of the upper slide.

Note that this theory will be valid only if $\tau_{1}$ is much larger than the characteristic time $\tau_{2}$ required to reach the stationary hydrodynamic regime. Now we know that [1] :

$$
\tau_{2}=\frac{d^{2} \rho}{\pi^{2} \eta} \text {. }
$$

Numerically we have typically $\eta=1$ poise, $\kappa=10^{7} \mathrm{~cm}^{-1}, B=10^{8} \mathrm{erg} / \mathrm{cm}^{3}, \rho=1 \mathrm{~g} / \mathrm{cm}^{3}$, $d=100 \mu \mathrm{m}$ and $\alpha=10^{-3} \mathrm{rad}$. whence $\tau_{1}=1 \mathrm{~s}$ and $\tau_{2}=10^{-5} \mathrm{~s}$. Thus the previous approach is perfectly justified.

3. Critical velocity for the appearance of an undulation instability. - During the shear, the smectic is subject to the uniaxial stress :

$$
\sigma_{z z}=\frac{\mu \kappa V}{2}\left[1-\exp \left(-\frac{t}{\tau_{1}}\right)\right]
$$

positive when the shear leads to a dilation of the sample, negative in the contrary case. It is well known, in the static case, that an undulation instability of the layers develops under dilation as soon as $\sigma_{z z}$ goes beyond a certain critical threshold [5]

$$
\sigma_{\mathrm{c}}=2 \pi \frac{\sqrt{K B}}{d} \text {. }
$$

This criterion remains valid under shear with a very good approximation [5] and allows us to define a critical velocity $V_{\mathrm{c}}$ under which the undulation instability does not appear :

$$
V_{\mathrm{c}}=\frac{4 \pi \sqrt{K B}}{d \mu \kappa} .
$$


If, on the other hand, $V>V_{\mathrm{c}}$ the instability develops as soon as $\sigma_{z z}=\sigma_{\mathrm{c}}$, which occurs at the critical time :

$$
t_{\mathrm{c}}=\tau_{1} \operatorname{Ln}\left(\frac{V}{V-V_{\mathrm{c}}}\right)=\frac{4 \pi}{\alpha V_{\mathrm{c}}} \sqrt{\frac{K}{B}} \operatorname{Ln}\left(\frac{V}{V-V_{\mathrm{c}}}\right) .
$$

We see that the critical velocity does not depend on the angle $\alpha$ and is directly connected to the permeability $\lambda_{\mathrm{p}}$. The parameters $K, B, \mu$ being known, it is sufficient to measure this critical velocity in order to obtain $\lambda_{p}$, which makes this method particularly interesting.

We see on the other hand that $t_{\mathrm{c}}$ is inversely proportional to $\alpha$. Hence the instability does not appear $\left(t_{\mathrm{c}} \rightarrow+\infty\right)$ when the slides are parallel $(\alpha=0)$.

With the previous numerical values, we obtain typically $V_{\mathrm{c}} \sim 10^{-3} \mathrm{~cm} / \mathrm{s}$.

4. Comparison with the classical lubrication theory. - In the foregoing we have admitted a simplified form of the velocity profile (cf. Eq. (2)). In order to justify this result, we remember that the dynamical equations differ from those of a viscous liquid by a term describing an additional stress gradient $\mathbf{g}=(0,0, g)$ which is significantly different from 0 only in a permeation layer, located in the middle of the specimen, of thickness $\sqrt{\kappa^{-1} \Lambda}$ of the order of a few hundred layers. Outside this zone $g$ vanishes and we are led again to the classical lubrication theory [1]. We obtain :

$$
V_{x}=V \frac{z}{d}-\frac{3}{2} V \frac{\alpha}{d^{3}}(L-2 x) z(z-d) \neq V \frac{z}{d}
$$

The difference with equation (2) amounts to a few $\%$, taking typical values $L=5 \mathrm{~mm}, d=100 \mu \mathrm{m}$ and $\alpha=10^{-3} \mathrm{rad}$.

As to the pressure it is given by :

$$
P-P_{0}=-3 \mu V \frac{\alpha}{d^{3}}(L-x) x
$$

It is instructive to calculate the force $F$ that the smectic exerts normally on the slides :

$$
F=\int_{0}^{L}\left(P-P_{0}-\sigma_{z z}\right) \mathrm{d} x=-\frac{1}{2} \mu\left(\frac{L}{d}\right)^{3} V \alpha-\frac{1}{2} \mu \kappa L V\left[1-\exp \left(-\frac{B \alpha}{\mu \kappa d} t\right)\right] .
$$

In this equation we recognize the conventional pressure term $F_{\mathrm{p}}$ to which is added a purely smectic term $F_{\mathrm{e}}$ related to the bulk elasticity and of the same sign as the previous one : therefore the lubrication phenomenon appears in the same sense as shear $(V<0)$ in the classical and the smectic cases, as expected. With the previous numerical values and assuming that the stationary regime is reached, we have $F_{\mathrm{e}} / F_{\mathrm{p}} \sim 10^{4}$. Consequently the smectic character is highly dominating.

5. Experimental results. - The shear cell that we have used is described in reference [7]. The studied smectics are 8 CB (4-n-octyl-4' cyanobiphenyl) and AMC 11 (n-undecyl-p-azoxy $\alpha$-methyl). The deficiency of our cell in stiffness and stability leads to very approximate results. Nevertheless we have been able to verify the existence of a critical velocity which increases inversely to the thickness. For $8 \mathrm{CB}$ and at a room temperature we have measured $V_{\mathrm{c}} \sim 1.4 \times 10^{-3} \mathrm{~cm} / \mathrm{s}$ for a $140 \mu \mathrm{m}$ thick sample, which leads to $\kappa^{-1}=16 \AA$. For AMC 11 we find $\kappa^{-1} \sim 200 \AA$ at $85^{\circ} \mathrm{C}$. These orders of magnitude, although quite different, are perfectly reasonable and confirm the validity of the previous theory. 


\section{References}

[1] Batchelor, G. K., An Introduction to Fluid Dynamics (Cambridge University Press) 1970.

[2] Pershan, P. S., J. Appl. Phys. 45 (1974) 1590.

[3] Orsay Group on Liquid Crystals, J. Physique Colloq. 36 (1975) C1-305.

[4] Clark, N. A., Meyer, R. B., Appl. Phys. Lett. 22 (1973) 493.

Delaye, M., Ribotta, R., Durand, G., Phys. Lett. 44A (1973) 139.

[5] Oswald, P., Ben-Abraham, S. I., soumis au J. Physique.

[6] Martin, P., Parodi, O., Pershan, P., Phys. Rev. A 6 (1972) 2401.

[7] Oswald, P., Béhar, J., Kléman, M., submitted to Philos. Mag. 